\title{
Okul Müdürlerinin Yaratıcı Liderlik Özellikleri: Bir Ölçek Geliştirme Çalışması
}

\section{Rezzan UÇAR* ${ }^{*}$ Ebru SAĞLAM**}

Öz: $\mathrm{Bu}$ araştırmanın amacı okul müdürlerinin yaratıcı liderlik özelliklerini belirlemeye yönelik bir ölçek geliştirmektir. Bu amaçla ölçek taslağı öncelikle alan yazına dayalı olarak oluşturulmuş ve görüşlerini almak üzere uzmanlara sunulmuştur. Uzmanlardan elde edilen dönütler doğrultusunda ölçeğe son şekli verilmiş ve taslak ölçek 335 öğretmene uygulanarak elde edilen veriler analiz edilmiştir. Açımlayıcı faktör analizi sonucunda "girişimcilik ve etkili iletişim", "yeniliğe ve değişime açıklık" ve "farklılık" olmak üzere üç faktörlü toplam 29 maddelik bir yapı ortaya çıkmıştır. Elde edilen yapının doğruluğunu test etmek amacıyla doğrulayıcı faktör analizi yapılmış elde edilen veriler sonucunda modelin uyum indekslerinin kabul edilebilir olduğu belirlenmiştir. Doğrulayıcı faktör analizi açımlayıcı faktör analizini doğrulamıştır. Ölçeğin güvenirliği için de iç tutarlılık katsayısını elde etmeyi hedefleyen Cronbach alfa değeri ölçüt olarak hesaplanmıştır. Ölçeğin tümü için iç tutarlılık katsayısı .98, "girişimcilik ve etkili iletişim" için .97, "yeniliğe ve değişime açıllık" .97 ve "farklılık" için .80 olarak belirlenmiştir. Bu doğrultuda "Okul Müdürlerinin Yaratıcı Liderlik Özellikleri Ölçeği"nin okul müdürlerinin yaratıcı liderlik özelliklerini ölçebilecek geçerli ve güvenilir bir ölçme aracı olduğu sonucuna ulaşılmıştır.

Anahtar kelimeler: Yaratıcılık, yaratıcı liderlik, okul müdürü.

\section{The Creative Leadership Qualities of School Administrators: A Study of Developing a Scale}

Abstract: The aim of this study was to develop a scale stating creative leadership qualities of school administrators. Frame of the scale is set up based on related literature and after getting experts' ideas, last shape was given. For this, data collected from 335 teachers were analyzed.

\footnotetext{
* Dr. Öğr. Üyesi, Van Yüzüncü Y1l Üniversitesi, Eğitim Fakültesi, Eğitim Bilimleri Bölümü, Eğitim Yönetimi Anabilim Dalı, Van. ucarrezzan@gmail.com

** Van Yüzüncü Yıl Üniversitesi, Eğitim Bilimleri Enstitüsü, Eğitim Yönetimi Programı. ebruakbalikci@gmail.com
}

$\begin{array}{lll}\text { Gönderim:08.07.2018 Kabul:11.02.2019 } & \text { Yayı:15.03.2019 }\end{array}$


As a result of exploratory factor analysis, 29 total items' were clustered under three factors; ‘entrepreneurship and effective communication', 'openness to innovation and changes' and 'variety'. Confirmatory factor analysis was done to determine the accuracy of the structure and the alignment index of model was stated as acceptable. Confirmatory factor analysis verified exploratory factor analysis. Cronbach alpha value, aiming to produce internal consistency coefficient, was counted for reliability. The internal consistency coefficient is found .98 for the whole scale, .97 for 'entrepreneurship and effective communication' dimension, .97 for 'innovation and changes' dimension and .80 for 'variety' dimension. In this direction, the result of 'The Creative Leadership Qualities of School Administrators' Scale’ was found as a valid and reliable instrument.

Key words: Creativity, creative leadership, school administrator.

\section{Giriş}

Geçmişten günümüze yaşanan değişim ve yenileşme karşısında örgütlerin birbirleriyle yaşadıkları rekabeti sürdürmeleri, bu rekabetten galip çıkmaları, farklı bakış açılarına sahip olmaları ve her duruma kolayca uyum sağlayabilmeleri örgütte çalışan bireylerin sahip oldukları özelliklerine bağlı olarak değişmektedir. Çünkü örgütlerde farklılık yaratacak unsur çalışan bireylerin sahip olduğu özelliklerdir (Uçar, 2015). Her türlü bilgiye ulaşmanın kolaylıkla sağlandığı günümüzde artık orijinal, denenmemiş fikirlere ihtiyaç duyulmaktadır. Yani bireylerin yaratıcılıkları önem kazanmaktadır.

İngilizce "create", Latince "creare" sözcüğünden gelen "yaratıcılık" genel olarak yaratmak, doğurmak, meydana getirmek, bulmak, keşfetmek, yenilik yaratmak anlamlarına gelmektedir (Andreasen, 2013; Balay, 2010; Yanık, 2007). Yaratıcılık birçok çalışmada farklı şekillerde tanımlanmıştır. Harris (2009) yaratıcılığı, hissedilen ya da var olan durumlara karşı ortaya çıkan duygusal bir tepki olarak tanımlarken; Bentley (1999) bilginin alınması ve yeni bir şekil ya da yeni bir düşünce meydana getirene kadar yeniden düzenlenme süreci olarak; Amabile (1997) ise bilimden sanata, eğitime, iş alanına, günlük yaşama kadar insan faaliyetlerinin herhangi bir alanında orijinal, münasip fikirlerin üretimi olarak tanımlamaktadır.

Yaratıcılığın doğuştan bireyde var olduğu düşüncesi; modern çalışmalarla aşılmış, yapılan çalışmalar yaratıcılık özelliğinin sadece doğuştan var olmadığını, öğrenilebilen ve geliştirilebilen bir özellik olduğunu vurgulamışlardır (Harris, 2009; Ritter ve Ferguson, 
2017). Bu bağlamda yaratıcılık hem bir süreç olarak hem de kişisel ve çevresel faktörlerin 1şı̆̆ında ele alınmaktadır (Günaydın, 2011). Kişisel faktörler açısından değerlendirildiğinde yaratıcı bireyde bulunması gereken özelliklere ilişkin farklı görüşler mevcuttur. Yaratıcı bireylerin diğer bireylere oranla düşünme becerilerini daha çok kullandıkları, riski göze aldıkları, deneyim ve maceraya açık oldukları, dünyaya önyargılardan bağımsız taze ve özgün bir şekilde yaklaştıkları, keşfetmeyi sevdikleri, meraklı oldukları, dışarıdan dayatılan kurallar yerine kendi iç yönelimleri doğrultusunda hareket ettikleri ifade edilmektedir (Memduhoğlu, Uçar ve Uçar, 2017).

Yaratıcılık, belli bir kişiye ya da belli bir alana özgü bir özellik değildir. Bilim insanları, teknoloji uzmanları, iş adamları, eğitimciler herkes kendi yaptığı işte yaratıcı olabilir (Robinson, 2008). Ancak bireylerin yaratıcı olabilmeleri için olaylara, nesnelere, olgulara ilişskin kendilerine sorular sorması, dış dünya ile kendi duygu ve düşüncelerini etkileşime sokması gerekmektedir. Bu bağlamda desteklenen bireyler yaratıcı gücünü ortaya çıkarma ve geliştirme imkanına sahip olmaktadırlar (Turaşlı, 2012). Bilginin ve teknolojinin hızla geliştiği ve değiştiği, insan kaynaklarının kullanımının ihtiyaçlara göre yeniden yapılandırıldığı günümüzde düşünebilen, risk alabilen, üretebilen ve problem çözebilen insanlara duyulan gereksinim giderek artmaktadır (Tanju, 2012) ve bu özelliklerin ancak eğitimle geliştirilebilineceği düşünülmektedir (Sungur, 1992, Uçar, 2015).

Eğitim sistemleri bireylerin düşünce yapılarını geliştirmeyi, aklını çeşitli şekillerde kullanmayı, diğer kuşakların yaptıklarını yineleyen değil, yeni şeyler yapabilme yeteneği olan bireyler yaratmayı amaçlamaktadır (Yenilmez ve Yolcu, 2007). Bu bağlamda insan yaşamında önemli bir rolü olan eğitim örgütlerinde yenilikçi ve yaratıcı bireylere büyük oranda ihtiyaç duyulmaktadır (Mousavi, Heidary ve Pour, 2011). Eğitim örgütlerinde yaratıcılığı geliştirmede okul yöneticilerinin yaratıcı liderlik özellikleri ön plana çıkmaktadır (Zhang, Siribanpitak ve Charoenkul, 2018). Çünkü okullar bir yandan toplumdaki değişimlerden etkilenmekte, öte yandan toplumdaki değişimi sağlayıcı ya da hızlandırıcı bir rol üstlenmektedir. Okullar değişimi kolaylaştırma görevlerini yeniliğe açık insanlar yetiştirerek gerçekleştirmektedir. $\mathrm{Bu}$ bağlamda okullar toplumların itici gücü olmaktadır (Doğanay, 2000). Günümüzün en üst düzeyde verimlilik ve yaratıcılık beklenen kurumları olarak okullarda (Sungur, 2001) okul yöneticilerinin yaratıcı liderlik özellikleri hem öğrencilerin hem öğretmenlerin yaratıcılığını kolaylaştırmada önemli rol oynamaktadır (Zhang, Siribanpitak ve Charoenkul, 2018). 
Yaratıcı liderlik, yönetsel görevleri yeniden organize ederek üstün bir yetenek ve başarı ile yönetme sürecidir. Geniş bilgi ve eğitim düzeyine erişildiğinde, analiz ve sentez yeteneğine sahip, problemleri tanımlayabilen, yeni değişim yollarını kavramsallaştırabilen lider olunduğu takdirde yaratıcı liderlikten söz edilebilmektedir. Etkili yaratıcı liderlik özellikleri bir idareci ya da yönetici vasıflarından daha fazlasını gerektirmektedir (Sungur, 1992). Yaratıcı liderlik için öncelikle, yaratıcılığın oluşması ve gelişmesinde önemli bir yere sahip olan; yüksek bir kültürel birikim, azim, cesaret, kararlılık, hoşgörü, özgür ve bütüncül düşünebilme, geleceğe yönelik yepyeni ufuklar açabilecek vizyonel bakış açısı tutum ve davranış bütünlüğü gerekli olmaktadır (Marşap, 2009). Yaratıcı liderlik, hayallerden ve düşüncelerden sorumluluğa doğru firsatları yaratmak ve her düzeyde direnmeyi engelleyen sorunlarla mücadele etmektir (Stoll ve Temperley, 2009). Yaratıcı liderlik, organizasyonda yönetsel görevleri yerinde organize ederek üstün bir yetenek ve başarı ile yönetme sürecidir (Marşap, 2009). Bugünün karmaşık problemlerini çözmeyi içeren yaratıcı liderlik yaklaşımının, dikkat etme, ilgilenme, kişiselleştirme, hayal etme, ciddiye alma, birlikte araştırma ve zanaatkar olmaya gereksinimi vardır (Palus ve Horth, 2005). Yaratıcı liderlik farklı insanlarla iletişim kurabilmeyi, zaman, kaynak, firsat ve ortak öğrenmelerin gerçekleştiği boşlukları etkili bir biçimde doldurmayı gerektirmektedir (Harris, 2009). Aslında, yaratıcı liderlik farklı bakış açılarını ve düşünme yollarını kendi öz bilinciyle birleştirerek yenilikçi çözüm yolları bulabilme becerisidir (Macbean, 2014). Bu bağlamda yaratıcı liderin girişimci ve etkili bir iletişim becerisine sahip olma, yeniliğe ve değişime açık olma, farklılığı sağlayarak kalıpların dışına çıkma özelliklerini barındırması gerektiği ifade edilebilir.

Eğitimde yaratıcı liderlik ise birçok anlama gelebilmektedir. Eğitimde yaratıcı liderlik sadece problem çözme değildir, problemi bulma, tanımlama, ortamda var olan tehditleri saptayarak düzeltip eğitim alan herkes için daha iyi bir gelecek hazırlamaktır (Stoll ve Temperley, 2009). Okulda yaratıcı lider okuldaki iletişim sisteminin etkili işlemesine, takım çalışmasının özendirilmesine, hataların hoş görülmesine, fikirlerin özgürce ifade edilmesine ve okulda demokratik bir anlayışın ortaya çıkmasına olanak sağlamaktadır (Memduhoğlu, Uçar ve Uçar, 2017).

Eğitim örgütleri olarak okulların hizmet ettiği çevrenin değişen istek ve ihtiyaçlarına olabildiğince kısa zamanda ve etkili olarak cevap verme (Çolakoğlu, 2005), nitelikli eğitimle üstün nitelikli bireyler yetiştirme (Can, 2013), değişime ayak uydurma ve toplumun 
yenilenmesine öncülük etme (Özdemir, 2000) gibi hususları amaç edinmesi ve okulların özgün yapısı dikkate alındığında okul yöneticilerinin yaratıcı liderlik özelliklerine sahip olması gerektiği ifade edilebilir. Çünkü eğitimin kalbi öğrenci ve öğretmen arasındaki ilişkide atmaktadır. Eğer bu ilişki yoksa sistem bir işe yaramıyor demektir. Eğitim; hevesli öğrenciler ve merak uyandıran öğretmenlerin olduğu her yerde gerçekleşir. Asıl görev öğrenciler ve okul paydaşları arasındaki ilişkinin gelişebileceği bir ortam yaratmaktır (Robinson ve Aronica, 2017). Bu bakımdan okul yöneticilerinin yaratıcı liderlik özellikleri önem taşımaktadır. Okullarda yaratıcı liderlik özelliklerine sahip okul yöneticilerinin bulunması okulu yönetme ve yönlendirmede, öğrenci ve öğretmenlerle iletişimde, öğrenci ve öğretmenlerin yaratıcılıklarının desteklenmesinde, görev yaptığı okulun diğer okullar arasında özgün bir yapıya kavuşmasında, problemleri fark etme ve problemlere farklı ve pratik çözümler geliştirmede önemli katkılar sağlayabilir. Bu bağlamda okul müdürlerinin yaratıcı liderlik özelliklerini belirlemeyi sağlayacak ölçütlerden oluşan yapıların geliştirilmesine gereksinim duyulduğu ifade edilebilir.

\section{Araştırmanın Amacı}

$\mathrm{Bu}$ araştırmanın amacı okul müdürlerinin yaratıcı liderlik özelliklerini belirlemeye yönelik bir ölçek geliştirmektir. Ölçek, okullarda görev yapan öğretmenlere yönelik yapılandırılmıştır.

\section{Yöntem}

$\mathrm{Bu}$ başlık altında, araştırmanın deseni ve çalışma grubu, ölçme aracının geliştirilmesi, verilerin toplanması ve verilerin çözümlenmesinde kullanılan teknikler aktarılmıştır.

\section{Araştırmanın Deseni ve Çalışma Grubu}

Tarama modelinde gerçekleştirilen çalışmanın çalışma grubunu Van İli Erciş İlçesi resmi okullarda görev yapan 335 öğretmen oluşturmaktadır.

\section{Ölçeğin Geliştirilmesi}

Okul müdürlerinin yaratıcı liderlik özellikleri ölçeği için yerli ve yabancı alan yazın incelemesi doğrultusunda 96 maddeden oluşan bir ölçek taslağı oluşturulmuştur. İkinci aşamada anlam bozukluğu taşıyan konu ile doğrudan ilgisi olmayan ve benzerlik taşıyan ifadeler arasında eleme yapılması sonucunda taslak ölçek 80 maddeye indirilmiştir. Bu taslak 
araç, üçüncü aşamada, eğitim bilimleri, araştırma yöntemleri ve istatistik alanlarında uzman 9 öğretim üyesinin görüşüne sunulmuştur. Uzmanların görüşlerinin alınmasında hazırlanan formda üçlü derecelendirmeye yer verilmiştir. Her bir madde için "uygun", "uygun değil" ve "kısmen uygun" seçeneklerinden birini seçmeleri istenmiştir. Uzman incelemesinden sonra her bir madde için kapsam geçerlik oranı hesaplanmıştır. Kapsam geçerlik oranı, ölçek maddesinin ölçülmek istenen özelliği kapsama ya da maddenin ilgili yapıyı yordama gücünü belirlemek amacıyla yapılan bir ön çalışmadır. Kapsam geçerlik oranını hesaplarken bir maddeye ilişkin ifadeyi uygun gören uzman sayısının tüm uzman sayısının yarısına oranının bir eksiği tespit edilerek değerlendirme yapılmaktadır (Lawshe, 1975). Bu doğrultuda yapılan hesaplamalar sonucunda 0.75 'in altında değer alan maddeler ölçekten çıkarılmıştır. Elde edilen kapsam geçerlik oranları neticesinde yapılan düzenlemeler doğrultusunda söz konusu ölçekteki bazı ifadelerin çıkarılması ile madde sayısı 65'e indirilerek taslak ölçek uygulamaya hazır hale getirilmiş ve "Okul Müdürlerinin Yaratıcı Liderlik Özellikleri Ölçeği” (OMYLÖÖ) olarak adlandırılmıştır. Ölçekteki soruların anlaşılırlığı ve cevaplama süresini değerlendirmek amacıyla 10 öğretmene ön uygulama yapılarak ölçeğe son şekli verilmiştir.

Likert tipi beşli derecelendirme ile katılımcıların verilen ifadelere ilişkin tepkilerini belirlemeyi sağlayacak şekilde oluşturulan ölçek, tamamen katılıyorum (5), çok katılıyorum (4), orta düzeyde katılıyorum (3), az katıllyorum (2) ve hiç katılmıyorum (1) seçeneklerinden oluşmuştur.

\section{Verilerin Toplanması}

Son şekli verilen ölçek, geçerlik çalışmasını sürdürmek ve güvenirliğini belirlemek üzere 2017-2018 eğitim-öğretim yılında Van İli Erciş İlçesi’nde yer alan okullarda görev yapan 380 öğretmene uygulanmıştır. Geri dönenler içinde eksik doldurulanlar elendikten sonra 335 ölçek formu değerlendirilmiştir.

\section{Verilerin Analizi}

Örneklem sayısının faktör analizi için uygunluğunu belirlemek için KMO ve Barlett küresellik testi yapılmıştır (Büyüköztürk, 2010; Izquierdo, Olea ve Abad, 2013), toplanan verilerin KMO değeri .978, ve Barlett Küresellik Testi sonucu $(\chi 2=14916,213 ; p<0,05)$ ise anlamlı bulunmuştur. $\mathrm{Bu}$ değer veri setinin faktör analizi için uygun olduğunu göstermektedir.

KMO değerinin uygun olduğunun görülmesinin ardından, ölçeklerin yap1 geçerliliği için açımlayıcı ve doğrulayıcı faktör analizleri yapılmıştır. Açımlayıcı faktör analizinde temel 
bileşenler analizi doğrulayıcı faktör analizinde ise Ki-Kare Uyum Testi (Chi-Square Goodness, $\chi 2$ ), İyilik Uyum İndeksi (Goodness of Fit Index, GFI), Düzeltilmiş Uyum İndeksi (Adjusted Goodness of Fit Index, AGFI), Karşılaştırmalı Uyum İndeksi (Comparative Fit Index, CFI), standardize edilmiş hataların ortalama karekökü (Standartized Root Mean Square Resudual, SRMR), normalleştirilmemiş uyum indeksi (Non-Normed Fit Index/ Tucker-Lewis Index, NNFI) ve Yaklaşık Hataların Ortalama Karekökü (Root Mean Square Error of Approximation, RMSEA) uyum istatistikleri değerlendirilmiştir. Ölçeğin güvenirliğgi için de iç tutarlılık katsayısını elde etmeyi hedefleyen Cronbach alfa değeri ölçüt olarak hesaplanmıştır.

\section{Bulgular}

Bu bölümde "Okul Müdürlerinin Yaratıcı Liderlik Özellikleri Ölçeği"nin geliştirilme aşamaları doğrultusunda yapılan geçerlik ve güvenirlik çalışmalarına yer verilmişstir.

\section{Okul Müdürlerinin Yaratıcı Liderlik Özellikleri Ölçeği'nin Geçerlik ve} Güvenirlik Çalışmaları

OMYLÖÖ'nin yapı geçerliği için açımlayıcı ve doğrulayıcı faktör analizleri yapılmıştır.

\section{Açımlayıcı Faktör Analizi}

Açımlayıcı faktör analizi uygulaması ile OMYLÖÖ’nin faktör yapısı saptanmaya çalışılmıştır. Faktör analizi, ölçek geliştirmeye ilişkin çalışmalarda yaygın olarak kullanılmaktadır (Gorsuch, 1997). Büyük veri setlerini "azaltma" ya da küçük bileşenler kümesi haline getirerek veriyi özetleme tekniği olarak tanımlanan faktör analizi (Pallant, 2005) ile ölçme aracındaki maddelerin kaç alt başlıkta toplanacağını ve aralarında ne tür bir ilişki olduğunu belirlemeye çalış1lır (Seçer, 2013). Veri seti üzerinde gerçekleştirilen açımlayıcı faktör analizi ile 65 maddeden oluşan OMYLÖÖ’nin tek ya da çok faktörlü olup olmadığı belirlenmeye çalışılmıştır. Bu doğrultuda, toplanan veriler üzerinde bir faktör analiz tekniği olan temel bileşenler analizi uygulanmış; ölçeğin birbirinden bağımsız alt faktörlerinin olup olmadığını belirlemek amacıyla varimax dik döndürme yöntemi kullanılmıştır.

Alan yazında, ölçek geliştirmede herhangi bir maddenin ölçekte yer almasına karar verilirken faktör yük değerinin .45 ya da daha yüksek olmasının seçim için iyi bir ölçüt 
olacağı belirtilmektedir (Bayram, 2009; Büyüköztürk, 2010). Diğer taraftan herhangi bir maddenin ölçekte yer almasına karar verilirken faktör yük değeri ölçütünün yanı sıra, bir maddenin yüksek iki yük değeri arasındaki farkın en az .10 olmasına dikkat edilmesi gerekmektedir. Buna göre çok faktörlü bir yapıda birden çok faktörde yüksek yük değeri veren madde, binişik bir madde olarak tanımlanmakta ve ölçekten çıkarılması gerektiği açıklanmaktadır (Akbulut, 2009; Tavşancıl, 2010). Bu bağlamda, çalışmada yapılan ilk analizler sonucunda; 36 madde yukarıda belirtilen ölçütleri karşılamadığından ölçekten çıkartılmıştır.

Ölçeğin faktör yapısını belirlemek üzere gerçekleştirilen temel bileşenler analizi neticesinde ölçek, 29 maddeden oluşan ve üç faktöre sahip bir yap1 göstermiştir. Ölçekte yer alan 29 maddenin faktör yük değerlerinin .50'nin üzerinde olduğu saptanmıştır. Söz konusu maddelerin faktör dağılımı ve faktör yük değerleri Tablo 1'de verilmiştir.

Tablo.1 Okul Müdürlerinin Yaratııı Liderlik Özellikleri Ölçeği Faktör Yapısı ve Madde Toplam Korelasyonları

\begin{tabular}{lllcc}
\hline Madde No & Faktör1 & Faktör2 & Faktör3 & Madde Toplam Korelasyonu \\
\hline M58 &, 767 & &, 821 \\
M34 &, 755 & &, 819 \\
M30 &, 753 & &, 816 \\
M33 &, 752 & &, 822 \\
M54 &, 746 & &, 837 \\
M57 &, 715 & &, 803 \\
M59 &, 714 & &, 837 \\
M46 &, 711 & &, 811 \\
M37 &, 655 & &, 849 \\
M40 &, 649 & &, 709 \\
M53 &, 649 & &, 817 \\
M49 &, 641 & &, 861 \\
M38 &, 611 & &, 784 \\
M41 &, 601 & &, 746 \\
M3 & & &, 809 \\
M8 & & &, 858 \\
M6 &, 777 & &, 872 \\
M4 &, 762 & &, 813 \\
M5 &, 724 & &, 854 \\
M1 &, 722 & &, 756 \\
M2 &, 715 & &, 813 \\
M7 &, 713 & &, 829 \\
M9 &, 708 & &, 860 \\
M18 &, 706 & &, 844 \\
M17 &, 656 & &, 614 \\
M63 & & &, 688 \\
M19 & & &, 712 \\
M64 & &, 799 & \\
M11 & &, 672 & \\
\hline
\end{tabular}


Tablo 1 incelendiğinde, ölçme aracında yer alan maddeler birbirinden bağımsız üç faktörde toplanmıştır. Maddelerin faktör yük değerleri .598 ile .799 arasında değişen yüksek değerlere sahiptir. Analiz sonucunda birinci faktör 14, ikinci faktör 11 ve üçüncü faktör 4 maddeden oluşmuştur. Ölçeği oluşturan faktörler, maddelerin içerdiği ifadeler dikkate alınarak isimlendirilmiştir. Bu bağlamda birinci faktör "girişimcilik ve etkili iletişim”; ikinci faktör “yeniliğe ve değişime açıklık” ve üçüncü faktör ise “farklılık” olarak isimlendirilmiştir. Ayrıca, ölçeği oluşturan maddelerin madde toplam korelasyonlarına bakılmıştır. İlişki katsayıları incelendiğinde $\mathrm{r}=.446$ ile .861 arasında değiştiği görülmektedir. $\mathrm{Bu}$ bulgular doğrultusunda her bir maddenin toplam ölçek puanı ile yüksek düzeyde bir korelasyona sahip olduğu ifade edilebilir.

Okul müdürlerinin yaratıcı liderlik özellikleri ile ilgili olarak elde edilen iç tutarlılık (Cronbach alfa) değeri ve her bir faktörün ayrı olarak açıkladığı varyanslar Tablo 2'de verilmiştir.

Tablo 2. Okul Müdürlerinin Yaratıcı Liderlik Özellikleri Ölçeği Alt Faktörlerinin Açıkladığı Varyans Oranları, Özdeğerleri ve Alfa Katsayıları

\begin{tabular}{lccc}
\hline Faktör & Özdeğerler & Açıkladı̆̆ı Varyans (\%) & Cronbach Alfa \\
\hline Girişimcilik ve Etkili İletişim & 19,036 & 31,993 &, 97 \\
Yeniliğe ve Değişime Açıklık & 1,191 & 28,219 &, 97 \\
Farklılık & 1,059 & 13,245 &, 80 \\
\hline Toplam & & $\mathbf{7 3 , 3 9 7}$ & $\mathbf{, 9 8}$
\end{tabular}

Tablo 2'de görüldüğü üzere, her faktörün açıkladığı varyans oranı, sırasıyla, birinci faktörde \% 31,993; ikinci faktörde \% 28,219 ve üçüncü faktörde ise \% 13,245 şeklindedir. Her üç faktörün açıkladığı toplam varyans ise \% 73,397 olarak belirlenmiştir. Birinci faktör için hesaplanan Cronbach Alfa katsayısı .97 iken, ikinci faktör için .97, üçüncü faktör için .80 ve toplam ölçek için ise .98 olarak bulunmuştur. Cronbach Alfa katsayısının .70 ve daha yüksek olması test puanlarının güvenirliği için genel olarak yeterli görülmektedir (Büyüköztürk, 2010). Bu bağlamda OMYLÖÖ'nin üç boyutu ve toplam ölçek puanındaki değerler dikkate alındığında ölçeğin güvenilir olduğu ifade edilebilir.

Ölçeğe ilişkin faktörlerin birbirleri ile ve toplam ölçek puanı ile korelasyonları incelenmiş ve Tablo. 3'de verilmiştir. 
Tablo.3 Okul Müdürlerinin Yaratıcı Liderlik Özellikleri Ölçeği Alt Boyutları Arasındaki Korelasyon Katsayıları (N=335)

\begin{tabular}{lccrc}
\hline Faktörler & $\begin{array}{l}\text { Girişimcilik ve } \\
\text { Etkili İletişim }\end{array}$ & $\begin{array}{l}\text { Yeniliğe ve } \\
\text { Değişime Açıklık }\end{array}$ & Farklılık & Toplam \\
\hline Girişimcilik ve Etkili İletişim & 1 &, $89^{* *}$ &, $73^{* *}$ &, $97^{* *}$ \\
Yenilik ve Değiş̧ime Açıklık & & 1 &, $74^{* *}$ &, $96^{* *}$ \\
Farklılık & & & 1 &, $81^{* *}$ \\
Toplam & & & 1 \\
\hline \multicolumn{1}{c}{$\mathrm{p}<.01$} & & &
\end{tabular}

Tablo. 3'e göre ölçekte yer alan faktörler birbirleri ile ve toplam ölçek puanı ile pozitif yönde yüksek düzeyde anlamlı ilişki göstermektedir.

\section{Doğrulayıcı Faktör Analizi}

Doğrulayıcı (confirmatory) faktör analizi, verinin temelindeki yapıyı değerlendiren açımlayıcı faktör analizinin bir uzantısıdır. Açımlayıcı faktör analizi belirleme işlevini ve hipotez kurmaya yönelik bilgi edinilmesini sağlamayı amaçlarken, doğrulayıcı faktör analizi; belirlenen faktörler arasında yeterli düzeyde bir ilişkinin olup olmadığını, hangi değişkenlerin hangi faktörlerle ilişkili olduğunu, faktörlerin birbirinden bağımsız olup olmadığını ve faktörlerin modeli açıklamakta yeterli olup olmadığını sınamak amacıyla kullanılır (Erkorkmaz, Etikan, Demir, Özdamar, Sanisoğlu, 2013; Gorsuch, 1997; Seçer, 2013). Bu çerçevede, elde edilen ölçme aracındaki faktör yapısının uygunluğu doğrulayıcı faktör analizindeki birtakım ölçütlerle test edilmektedir (Kayri ve Günüç, 2009). Modelin uygunluğunu test etmede; ki kare, sınanan modelin karşılaştırmalı uyum indeksi (Comperative Fit Index-CFI), uyum iyiliği indeksi (Goodness of Fit Index-GFI), düzeltilmiş uyum indeksi (Adjusted Goodness of Fit Index-AGFI) modelin açıklanan kovaryans ile gözlenen kovaryansları arasındaki farkların ortalamasını veren standardize edilmiş hataların ortalama karekökü (Standartized Root Mean Square Resudual-SRMR), yaklaşık hataların ortalama kare kökü (Root Mean Square Error of Approximation-RMSEA), normalleştirilmemiş uyum indeksi (Non-Normed Fit Index/ Tucker-Lewis Index-NNFI) (Acun, Kapıkıran ve Kabasakal, 2013; Aytaç ve Öngen, 2012; Seçer, 2013) yaygın olarak kullanılmaktadır.

OMYLÖÖ’nin açımlayıcı faktör analizi neticesinde elde edilen model, doğrulayıcı faktör analizi ile (DFA) test edilmiştir. Elde edilen modelin uygunluğu (fit of model); CFI, GFI, AGFI, SRMR, RMSEA ve NNFI uyum ölçütleri ile test edilmiştir. Ölçeğe ilişkin yapılan doğrulayıcı faktör analizi sonuçları Tablo 4'de verilmiştir.

Tablo. 4 Okul Müdürlerinin Yaratıcı Liderlik Özellikleri Ölçeğine İlişkin Doğrulayııı Faktör Analizi Sonuçları 


\begin{tabular}{ccccccccc}
\hline$\chi^{2}$ & Sd & $\chi^{2} / \mathbf{s d}$ & CFI & GFI & AGFI & SRMR & RMSEA & NNFI \\
\hline 998.41 & 374 & 2,669 & 0,99 & 0,83 & 0,80 & 0.032 & 0.071 & 0.99 \\
\hline
\end{tabular}

Yapılan analizler sonucunda, modelin uygunluğuna yönelik hesaplanan uyum değerleri ki-kare/ serbestlik derecesi $\left(\chi^{2} / s d\right)$ 2.669; CFI için 0.99; GFI için 0.83; AGFI için 0.80; SRMR için 0.037; RMSEA için 0.071 ve NNFI için 0.99 olarak saptanmıştır. Ki kare istatistiği gözlenen değişkenlerin kovaryans yapıları ile modelin uygunluk gösterdiğine ilişkin hipotezi test eden bir tekniktir ve indeks uyum eksikliği olarak belirtilir. Ki-kare istatistiği toplamalı bir istatistik olduğundan değişken sayısı arttıkça yüksek çıkacağından Kikare/serbestlik derecesinden yararlanılır. Bu değer 5 değerinden küçük ise modelin uyum iyiliğine sahip olduğu, 3 değerinden daha küçük ise modelin çok iyi bir uyuma sahip olduğu kabul edilir (Doğan ve Başokçu, 2010). CFI 0 ile 1 değerleri arasında değişmektedir. CFI değerinin .97'den büyük olması mükemmel bir uyuma işaret etmektedir (Seçer, 2013). GFI değeri 0 ile 1 arasında değişmektedir (Jain ve Raj, 2014). Ancak .90'1 aşması mükemmel uyumu .85 ise kabul sınırı olarak düşünülmektedir (Seçer, 2013). AGFI değeri 0 ile 1 arasında değişmektedir. .90'1 aşması mükemmel uyumu, .85 ise kabul edilebilir uyumu işaret etmektedir (Schermelleh-Engel, Moosbrugger ve Müller, 2003). Ancak alan yazındaki bazı çalışmalarda AGFI değerinin .80 üzeri olması durumunun kabul edilebilir olduğu vurgulanmaktadır (Segars ve Grover, 1993; Doll, Xia ve Torkzadeh, 1994). SRMR değeri .05’den küçük olursa iyi uyumu göstermektedir. RMSEA değerleri .05'den küçük olursa iyi, .05 ile .08'in arasında olursa yeterli değerlendirilmektedir. NNFI değeri .97'in üzerinde olmas1 iyi uyumu göstermektedir (Schermelleh-Engel vd., 2003). Bu ölçütler dikkate alındığında doğrulayıcı faktör analizi ile elde edilen üç faktörlü yapının kabul edilebilir bir model olduğu ifade edilebilir.

Doğrulayıcı faktör analizinde yordanmaya çalışılan örtük değişken (latent variable) üç faktörlü bir yapıda bir bağımlı değişken ve örtük değiş̧keni açıklamaya çalışan maddeler de bağımsız değişken olarak kabul edildiğinde, modele ilişkin diyagram (path diagram) Şekil 1 'de gösterilmiştir.

Şekil 1'de her bir maddenin örtük bağımlı değişken üzerindeki etki miktarları ve korelasyon katsayıları görülmektedir. Girişimcilik ve etkili iletişim boyutunun maddelere ilişkin korelasyon katsayıları .72 ile .85 arasında; yeniliğe ve değişime açıklık boyutu .79 ile .91 arasında ve farklılık alt boyutunda .54 ile .85 arasında değişmektedir. Ölçekte yer alan tüm maddeler değerlendirildiğinde maddelerin korelasyon katsayılarının .54 ile .91 arasında 
değiştiği gözlenmiştir. Bulgular 1şığında, “Okul Müdürlerinin Yaratıcı Liderlik Özellikleri Ölçeği”nin okul müdürlerinin yaratıcı liderlik özelliklerini ölçebilecek, geçerli ve güvenilir bir ölçme aracı olduğu söylenebilir.

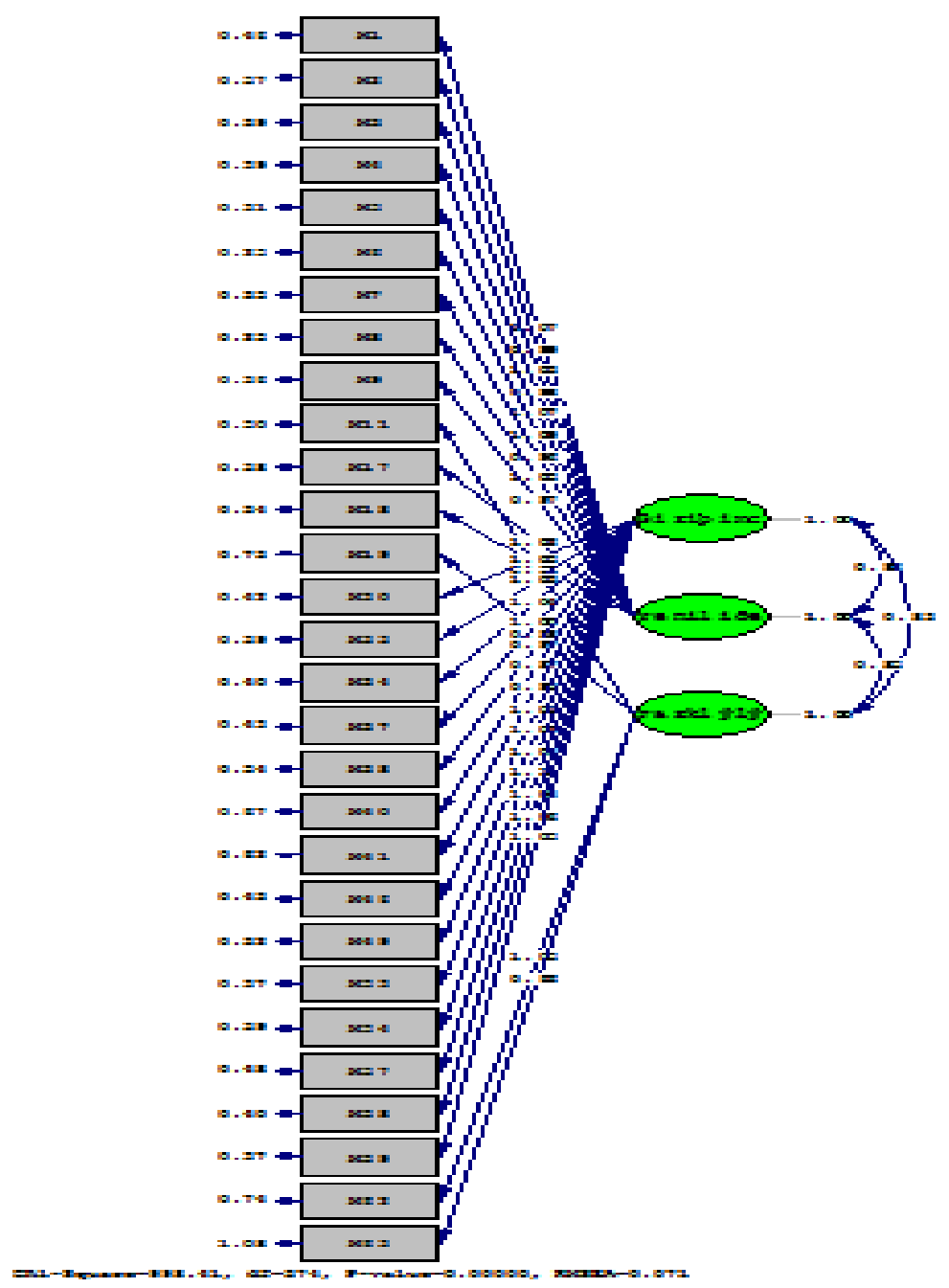

Şekil 1. OMYLÖÖ'nin doğrulayıcı faktör analizine ilişkin diyagram

\section{Sonuç}

Geçerlik ve güvenirlik analizleri yapılarak "Okul Müdürlerinin Yaratıcı Liderlik Özellikleri Ölçeği" şeklinde oluşturulan ve Likert tipinde beş derecelendirmeli olarak şekillendirilen ölçeğin yapı ve kapsam geçerliklerine bakılmıştır. Bu kapsamda ölçek açımlayıcı ve doğrulayıcı faktör analizine tabi tutulmuştur. Açımlayıcı faktör analizi sonucuna göre "Okul Müdürlerinin Yaratıcı Liderlik Özellikleri Ölçeği" 29 maddeden oluşan 
üç faktörlü bir yapı sunmaktadır. Birinci faktör 14, ikinci faktör 11 ve üçüncü faktör 4 maddeden oluşmaktadır. Faktörler içerdikleri maddeler dikkate alınarak girişimcilik ve etkili iletişim, değişime ve yeniliğe açıklık ve farklılık şeklinde adlandırılmıştır. Ölçekten alınacak toplam puan 29 ile 145 arasında değişmektedir. Üç faktörlü yapının açıkladığı varyans \%73,397'dir. Yapının doğruluğunu test etmek amacıyla doğrulayıcı faktör analizi yapılmış, analiz sonucunda $\chi^{2}$ /sd: 2.669; CFI: 0.99; GFI: 0.83; AGFI: 0.80; SRMR: 0.037; RMSEA: 0.071 ve NNFI: 0.99 olarak tespit edilmiştir. Doğrulayıcı faktör analizi ile elde edilen üç faktörlü yapının kabul edilebilir bir model olduğu belirlenmiştir. Ölçme aracının güvenirliğine ilişkin olarak yapılan analiz sonucunda Cronbach alfa katsayıları birinci faktör için .97, ikinci faktör için .97 ve üçüncü faktör için .80 olarak bulunmuştur. Analiz sonuçları doğrultusunda "Okul Müdürlerinin Yaratıcı Liderlik Özellikleri Ölçeği"nin okul müdürlerinin yaratıcı liderlik özelliklerini ölçebilecek geçerli ve güvenilir bir ölçme aracı olduğu ifade edilebilir.

\section{Makalenin Bilimdeki Konumu (Yeri)}

Eğitim Bilimleri/Eğitim Yönetimi Anabilim Dalı

\section{Makalenin Bilimdeki Özgünlüğü}

Bilimsel ve teknolojik alanda yaşanan hızlı değişim ve gelişmeler örgütsel etkinliklerde yeni, farklı, özgün çalışmaların önemini arttırmaktadır. Bir 2örgütün yaratıcı ve yenilikçi çalışmalar sergilemesi örgütte çalışanların yaratıcılığa teşvik edilebilen açık fikirli, yeniliğe ve gelişime önem veren, çalışanlarını cesaretlendiren ideal bir ortama sahip olmasına bağlıdır. Bu ortamı sağlamada yaratıcı liderlik özellikleri önem taşımaktadır. Bu bağlamda okul müdürlerinin okulu yönlendirmede yaratıcı liderlik özelliklerinin belirlenmesi gerektiği düşünülmektedir. Okul müdürlerinin yaratıcı liderlik özelliklerini belirlemeye yönelik bir ölçek geliştirmek amacıyla gerçekleştirilen çalışmanın alan yazına katkı sağlayacağı değerlendirilmektedir. 


\section{Kaynakça}

Acun, N., Kapıkıran, Ş. ve Kabasakal, Z. (2013). Merak ve keşfetme ölçeği II: Açımlayıcı ve doğrulayıcı faktör analizleri ve güvenirlik çalışması. Türk Psikoloji Yazıları, 16(31), 74-85.

Akbulut, Y. (2010). Sosyal bilimlerde SPSS uygulamaları. İstanbul: İdeal Yayınc1lık.

Amabile, T.M. (1997). Motivating creativity in organizations: On doing what you love and loving what you do. California Management Review, 40(1), 39-58.

Andreasen, A. (2013). Yaratıcı Beyin. (Çev. K. Güney), Ankara: Arkadaş Yayınevi.

Aytaç, M. ve Öngen, B. (2012). Doğrulayıcı faktör analizi ile yeni çevresel paradigma ölçeğinin yapı geçerliliğinin incelenmesi. İstatistikçiler Dergisi, 5, 14-22.

Balay, R. (2010). Öğretim elemanlarının örgütsel yaratıcılık algıları. Ankara Üniversitesi Eğitim Bilimleri Fakültesi Dergisi, 43(1), 41-78.

Bayram, N. (2009). Sosyal bilimlerde SPSS ile veri analizi. Bursa: Ezgi Kitabevi.

Bentley, T. (1999). Takımınızın yeteneklerini geliştirmede yaratıcılık. (Çev: O. Yıldırım), İstanbul: Hayat Yayınları.

Büyüköztürk, Ş. (2010). Sosyal bilimler için veri analizi el kitabı. Ankara: Pegam Akademi Yayınları.

Can, N. (2013). Öğretmen liderliği. Ankara: Pegem Akademi.

Çolakoğlu, M. (2005). Eğitim örgütlerinde değişim ve liderlik. Hasan Ali Yücel Eğitim Fakültesi Dergisi, 1, 63-77.

Doll, W.J., Xia, W. ve Torkzadeh, G. (1994). A Confirmatory Factor Analysis of the EndUser Computing Satisfaction Instrument. MIS Quarterly, 18(4), 453-461.

Doğan, N. ve Başokçu, T.O. (2010). İstatistik tutum ölçeği için uygulanan faktör analizi ve aşamalı kümeleme analizi sonuçlarının karşılaştırılması. Eğitimde ve Psikolojide Ölçme ve Değerlendirme Dergisi,1(2), 65-71.

Doğanay, A. (2000). Yaratıcı öğrenme. A. Şimşek (Ed). Sınıfta demokrasi içinde (s.1171210). Ankara: Eğitim-Sen Yayınları.

Erkorkmaz, Ü., Etikan, İ., Demir, O., Özdamar, K. ve Sanisoğlu, S.Y. (2013). Doğrulayıc1 faktör analizi ve uyum indeksleri. Türkiye Klinikleri J MED Sci, 33(1), 210-223.

Gorsuch, R.L. (1997). Exploratory factor analysis: İts role in item analysis. Journal of Personality Assessment, 68(3), 532-560.

Günaydın, H. (2011). Yaratıcı yönetim. İstanbul: IQ Kültür Sanat Yayıncılık.

Harris, A. (2009). Creative leadership, developing future leaders. Management in Education, 23(1), 9-11.

Izquierdo, I., Olea, J. ve Abad, F.J. (2014). Exploratory factor analysis in validation studies: Uses and recommendations. Psicothema, 26(3), 395-400.

Jain, V. ve Raj, T. (2013). Evaluating the variables affecting flexibility in FMS by exploratory and confirmatory factor analysis. Global Journal of Flexible Systems Management, 14(4), 181-193. 
Kayri, M. ve Günüç, S. (2009). İnternet bağımlılık ölçeğinin Türkçeye uyarlanması: geçerlik ve güvenirlik çalışması. Ankara Üniversitesi Ĕgitim Bilimleri Dergisi, 42,(1), 157-175.

Lawshe, C. H. (1975). A quantitative approach to content validity. Personnel Psychology, 28, 563-575.

Macbean, A. (2014). Dancing into diversity: a curriculum for self-discovery,empathy, and creative leadership. Journal of Dance Education,14(3), 117-121.

Marşap, A. (2009). Yaratıcı liderlik. Ankara: Gazi Kitapevi.

Memduhoğlu, H. B., Uçar, R., ve Uçar, İ. H. (2017). Örnek uygulamalarla eğitimde yaratıcılık yaratıcı okul yaratıcı ögretmen. Ankara: Pegem Akademi.

Mousavi, S.H., Heidary, A., ve Pour F.K. (2011). The relationship between leadership styles and physical education teachers" creativity. International Journal of Academic Research in Business and Social Sciences, 1(3), 82-84.

Özdemir, S. (2000). Eğitimde örgütsel yenileşme. Ankara: PegemA Yayıncılık.

Pallant, J. (2005). SPSS Survival Manual. Australia: Allan\&Unwin.

Palus, C. J. ve Horth, D. M. (2005). Leading creatively. Ivey Business Journal, September/October, 1-8.

Ritter, S.M. ve Ferguson, S. (2017). Happy creativity: Listening to happy music facilitates divergent thinking. PLOS ONE 12(9), 1-14. https://doi.org/10.1371/journal.pone.0182210

Robinson, K. (2008). Yaratıcılık, aklın sınırları aşmak. (Çev. N. G. Koldaş), İstanbul: Kitap Yayinevi.

Robinson, K. ve Aronica, L. (2017). Yaratıcı öğrenciler. (Çev. D.Boyraz), İstanbul: Sola Yayınları.

Schermelleh-Engel, K., Moosbrugger, H. ve Müller, H. (2003). Evaluating the fit of structural equation models: Tests of significance and descriptive goodness-of-fit measures. Methods of Psychological Research Online, 8(2), 23-74.

Segars, A.H. \& Grover, V. (1993). Re-examining perceived ease of use and usefulness: a confirmatory factor analysis, MIS Quarterly, 17 (4), 517-525.

Seçer, İ. (2013). SPSS ve LISREL ile pratik veri analizi. Ankara: Anı Yayıncılık.

Stoll, L. ve Temperley, J. (2009). Creative leadership: a challenge of our times. School Leadership and Management, 29(1), 63-76.

Sungur, N. (1992). Yaratıcı Düşünce. İstanbul: Özgür Yayın Dağıtım.

Sungur, N. (2001). Yaratıcı okul düşünen sınıflar. İstanbul: Evrim Yayınları.

Tanju, E.H. (2012). Yaratıcı düşünme kuram ve yaklaşımları. E.Ç. Öncü (Ed.). Erken Çocukluk Döneminde Yaratıcılık ve Geliştirilmesi içinde, (17-46). Ankara: Pegem Akademi.

Tavşancıl, E. (2010). Tutumların ölçülmesi ve SPSS ile veri analizi. Ankara: Nobel Yayın Dağıtım. 
Turaşlı, N.K. (2012). Yaratıcılıkta temel kavramlar ve yaratıcılığın doğasını anlamak. E.Ç. Öncü (Ed.). Erken Çocukluk Döneminde Yaratıcılık ve Geliştirilmesi içinde. (s.1-15). Ankara: Pegem Akademi.

Uçar, R. (2015). İlkokul öğretmenlerinin dağıtımcı liderlik davranışları ile öğretmenlerin motivasyon ve yaratıcılık düzeyleri arasındaki ilişki. Yayımlanmamış doktora tezi. Dicle Üniversitesi, Diyarbakır.

Yanık, O. (2007). Yaratıcılık. İstanbul: Reklam Yaratıcıları Derneği.

Yenilmez, K. ve Yolcu, B. (2007). Öğretmen davranışlarının yaratıcı düşünme becerilerinin gelişimine katkısı. Ondokuz Mayıs Üniversitesi Sosyal Bilimler Dergisi, 18, 95-105.

Zhang, Q., Siribanpitak, P. ve Charoenkul, N. (2018). Creative leadership strategies for primary school principals to promote teachers' creativity in Guangxi, China. Kasetsart Journal of Social Sciences, 1-7. https://doi.org/10.1016/j.kjss.2018.08.007

\section{Extended Summary}

\section{Problem State}

Depending on person's quality who working in an organization having different points of views, maintaining a competition among organizations because of the innovation and changes from past to now, winning this competition and adapting to each situation easily become important. Since creating variety in organization becomes possible only by qualities of workers. More untried and original ideas are necessary nowadays for access to any information easy. So, creativity gains importance. The idea of 'creativity is congenital' has been changed with modern research. The studies emphasize that the quality of creativity is not only congenital, but also learnable and can be developed.

Education systems aim to developing person's thinking way, to use mind in different ways and to create people having a talent to make new things not repeating the same as in other generations. So, the creativity gains importance in education organizations. The creative leadership qualities of school administrators become the first step for developing creativity in education organizations. Creative school leadership has an important role to make easier environment for both teachers' and students' creativity. So, the development of the scale to determine the creative leadership qualities of school administrators is needed.

The aim of the study: The aim of this study is developing a measurement instrument to determine the creative leadership qualities of school administrators. 
Method. The working group of this study, designing in scanning model, is 335 teachers working at formal schools of Erciş, the district of Van. KMO and Barlett globosity test is done to determine the acceptability of the sampling number for factor analysis, for building validity, exploratory and confirmatory factor analysis are done. In exploratory factor analysis, basic component analysis and in confirmatory factor analysis, Chi-Square Goodness, $\chi 2$, Goodness of Fit Index, GFI, Adjusted Goodness of Fit Index, Comparative Fit Index, CFI, Standardized Root Mean Square Residuals, SRMR, Non-Normed Fit Index/Tucker-Lewis Index, NNFI, Root Mean Square Error of Approximation, RMSEA are evaluated. Cronbach alpha value, aiming to produce internal consistency coefficient, is counted for scale reliability.

Findings. The KMO value of collecting data is .978 and the result of Barlett globosity test is meaningful. This value shows that factor analysis is suitable. As a result of basic component analysis aiming to see the structure of scale factor, a scale has three factors and 29 items. Factor load values of 29 items are found over .50. The factors of scale are called by looking the statements of items. So, first factor 'openness to innovation and change', second factor 'variety' and third factor 'entrepreneurship and effective communication' are given as a name. The model of the Creative Leadership Qualities of School Administrators scale as finding the result of exploratory factor analysis is tested by confirmatory factor analysis. The fit of model and perfect harmony of the value of $\chi 2$ /sd, the perfect harmony of the CFI value, acceptable harmony of GFI value, good harmony of SRMR, acceptable harmony of RMSEA value and good harmony of NNFI are resulted. Generally the result values of confirmatory factor analysis are acceptable harmony. Cronbach alpha value, aiming to produce internal consistency coefficient, is counted for scale reliability and variances are examined for each factors separately. Variance rates for each factor are found respectively, first factor \%31,993, second factor \%28,293 and third one $\% 13,245$. The total variance is determined \%73,739 for each three factors. The internal consistency coefficient of Cronbach alpha is found .98 for the whole scale, .97 for 'entrepreneurship and effective communication', .97 for 'innovation and changes' and .80 for 'variety'. 


\section{Results and discussion}

The analysis of reliability and validity is done and the scale is shaped as 'The Creative Leadership Qualities of School Administrators' Scale'. Scope and building validity is examined for scale shaped as a 5 likert- type scale. So, the scale is analyzed by exploratory and confirmatory factor analysis. According to the results of analysis, The Creative Leadership Qualities of School Administrators' scale presents 29 items and three factors' structure. First factor is 14 items, second factor is 11 and the third factor is 4 items. So, the results show that The Creative Leadership Qualities of School Administrators' scale is a valid and reliable measurement instrument. This study may lead researchers who want to study in this subject in terms of determining the dimensions of subject. 
Ek 1. Okul Müdürlerinin Yaratıcı Liderlik Özellikleri Ölçeği

\section{OKUL MÜDÜRLERININ YARATICI LIDERLIK ÖZELLIKLERI ÖLÇEĞi}

\section{Okul müdürüm,}

1. farklılıklara karşı saygılıdır.

2. çatışmaları yapıcı şekilde çözer.

3. özgürce soru sorulabilecek bir ortam hazırlar.

4. yönetim sürecinde iletişim kanallarını etkili bir şekilde kullanır.

5. öğretmenlere destekleyici eleştiriler sunar.

6. yaptığı çalışmalarda eleştirilmeye açıktır.

7. öğretmenleri eğitim sürecine daha coşkulu katılmaları yönünde özendirir.

8. karşılaştı̆̆

9. okula fayda sağlayacak konularda girişimci davranır.

10. gerektiğinde olaylara mizahi bakabilir.

11. hata ve yanlışlardan yeni bilgiler öğrenebileceğini düşünür.

12. yeni hedeflere ulaşmak için mevcut sınırların ötesine geçmeye çalışır.

13. girişimde bulunurken hata yapmaktan korkmaz.

14. kendisine sunulan her türlü firsatı değerlendirir.

15. değişen koşullara hızla uyum sağlar.

16. okulun amaçlarına ulaşmasında yaratıcı yollar geliştirir.

17. değişim için yeni yollar ortaya koyar.

18. karşılaştığ1 alışılmamış fikirleri değerlendirir.

19. özgün çalışmalarda öğretmenlerin bir yardımcısıdır.

20. yaratıcı fikirlerin ortaya çıkmasında esin kaynağıdır.

21. farklı fikirlerle gündeme gelmekten hoşlanır.

22. okulda eğitim öğretim faaliyetlerine ilişkin farklı uygulamaları destekler.

23. eğitim öğretim sürecinde karşılaştığı problemleri farklı şekillerde ele alır.

24. hayalleri yaşama geçirecek firsatlar yaratır.

25. engellerin üstesinden gelecek yaratıcı düşünceler ortaya koyar.

26. kendi gündemini kendisi oluşturur.

27. çevresindekilerden farklı düşünür.

28. okulda başkaları tarafından çılgınca karşılanabilecek aktivitelere yer verir.

29. okulda ortaya çıkan problemlere ilişkin ilginç çözüm önerileriyle herkesi şaşırtır. 